\title{
CXCR4 antibody treatment suppresses metastatic spread to the lung of intratibial human osteosarcoma xenografts in mice
}

\author{
Patrick Brennecke $\cdot$ Matthias J. E. Arlt • Carmen Campanile $\cdot$ Knut Husmann • \\ Ana Gvozdenovic • Tiziana Apuzzo • Marcus Thelen • Walter Born • \\ Bruno Fuchs
}

Received: 27 May 2013/ Accepted: 18 December 2013/Published online: 4 January 2014

(C) The Author(s) 2014. This article is published with open access at Springerlink.com

\begin{abstract}
Current combined surgical and neo-adjuvant chemotherapy of primary metastatic osteosarcoma (OS) is ineffective, reflected by a 5-year survival rate of affected patients of less than $20 \%$. Studies in experimental OS metastasis models pointed to the CXCR4/CXCL12 homing axis as a novel target for OS metastasis-suppressive treatment. The present study investigated for the first time the CXCR4-blocking principle in a spontaneously metastasizing human 143B OS cell line-derived orthotopic xenograft mouse model. The highly metastatic $143 \mathrm{~B}$ cells, unlike the parental non-metastatic HOS cells, express functional CXCR4 receptors at the cell surface, as revealed in this study by RT/PCR of gene transcripts, by FACS analysis with the monoclonal anti CXCR4 antibody 12G5 (mAb 12G5) and by CXCL12 time- and dose-dependent stimulation of AKT and ERK phosphorylation. A significantly $(p<0.05)$ higher CXCL12 dose-dependent chemotactic response of 143B compared to HOS cells in a Boyden chamber trans-well migration assay suggested a crucial role of the CXCL12/CXCR4 homing axis in 143B cell lung metastasis. Repetitive treatment of mice with 143B cellderived intratibial tumors given intravenous bolus injections of mAb12G5 indeed inhibited significantly $(p<0.01)$ the number of X-gal-stainable lung micrometastases of
\end{abstract}

P. Brennecke - M. J. E. Arlt · C. Campanile - K. Husmann ·

A. Gvozdenovic · W. Born · B. Fuchs $(\bowtie)$

Laboratory for Orthopedic Research, Department of

Orthopedics, Balgrist University Hospital, 8008 Zurich,

Switzerland

e-mail: bfuchs@research.balgrist.ch

T. Apuzzo $\cdot$ M. Thelen

Institute for Research in Biomedicine, 6500 Bellinzona,

Switzerland
lacZ-transduced 143B cells. Antibody treatment had also a mild inhibitory effect on primary tumor growth associated with remarkably less osteolysis, but it did not affect the number of developing lung macrometastases. In conclusion, these results demonstrate considerable potential of high-affinity CXCR4-blocking agents for OS tumor cell homing suppressive treatment in metastasizing OS complementary to current (neo)-adjuvant chemotherapy.

Keywords CXCR4-CXCL12 axis - Lung metastases . lacZ transduction - Osteosarcoma mouse model

$\begin{array}{ll}\text { Abbreviations } \\ \text { OS } & \text { Osteosarcoma } \\ \text { GAPDH } & \text { Glyceraldehyde-3-phosphate dehydrogenase } \\ \text { FACS } & \text { Fluorescence-activated cell sorting } \\ \text { BSA } & \text { Bovine serum albumin }\end{array}$

\section{Introduction}

Osteosarcoma (OS) is the most common primary bone neoplasia in children and young adolescents [1]. It has an incidence of 3 persons per million and year and a median peak at 16 years [2]. Multi-agent chemotherapy resulted in disease-free survival of $60-70 \%$ of the patients with localized disease [3]. These improvements made limb sparing surgery possible in $85-90 \%$ of the cases without compromising the outcome compared to amputation [4]. Despite this progress for patients with localized disease, patients with metastases still have a very low mean 5-year survival rate of approximately $20 \%$ [5-7]. The low survival rate of patients with metastatic disease is in part related to the fact that, until now, effective treatment 
targeting clinically non-detectable micro-metastases does not exist $[8,9]$. Consequently, these non-treatable metastases eventually grow to life-threatening lung nodules with a fatal outcome.

Metastasis is a complex multistep process that includes local tissue invasion of metastatic cells, their survival in the circulation, "homing" to and extravasation in a secondary organ and proliferation/growth at the metastatic sites [10, 11]. Chemokines interacting with chemokine receptors expressed by metastasizing tumor cells have crucial roles in directing migrating cells towards secondary organs. This is well documented for the chemokine CXCL12 and the chemokine receptor CXCR4. Mueller and co-workers initially postulated and discovered the CXCL12-CXCR4 homing axis in cancer metastasis [12, 13]. They demonstrated that CXCR4 expressing breast cancer cells preferentially migrated towards protein extracts of the lung, which expresses CXCL12 abundantly. Chemo-attraction by lung tissue extracts was abolished by CXCL12-neutralizing antibodies and by preincubation of breast cancer cells with CXCR4-blocking antibodies. Meanwhile, CXCL12 and CXCR4 were found to be instrumental for the development and progression of numerous different cancer types of epithelial, haematopoietic or mesenchymal origin [14-17]. It is noteworthy that, in normal physiology, CXCL12 and CXCR4 are important for the development of the CNS, the heart and the immune system. Moreover, they are involved in angiogenesis and stem cell trafficking and in proliferation and apoptosis.

At the cellular level, binding of CXCL12 to CXCR4 was shown to stimulate intracellular calcium flux, to activate AKT and ERK signaling pathways, and to up-regulate the formation of focal adhesions, which ultimately results in increased migration along gradients of locally expressed and secreted chemokines [18-20].

In OS patients, overall disease-free and metastasis-free survival was found to be inversely related to the expression of CXCR4-encoding mRNA in primary tumor tissue [21]. Furthermore, a tissue microarray analysis showed that CXCR4 expression correlated significantly with the expression of VEGF and that co-expression of CXCR4/ VEGF was an indicator for poor patient survival [22, 23]. Experimentally, proof of principle studies demonstrated that inhibition of CXCL12-evoked CXCR4 signaling by respective blocking agents inhibited metastasis in experimental models, achieved by intravenous tumor cell injection [24-26]. However, these models did not reproduce most of the complex processes characteristic for the metastatic cascade.

Consequently, we reinvestigated in the present study the metastasis suppressive potential of the CXCR4 blocking principle in a human 143B OS cell line-derived spontaneously metastasizing intratibial OS mouse model that closely mimics the human disease [27]. Primary intratibial tumors were provoked by injection of highly metastatic human 143B OS cells stably transduced with a constitutively expressed lacZ gene (143B-lacZ cells). This allowed post-mortem $X$-gal staining of primary tumor tissue and, more importantly, of lung metastases down to the single cell level as reported [28]. Tumor-bearing mice were treated at 4-day intervals by tail-vein bolus injections of the monoclonal anti-CXCR4 antibody (mAb 12G5), known to block the binding of CXCL12 to CXCR4 and to inhibit CXCL12-evoked chemotaxis in vitro [29, 30]. Tumorbearing mice injected with control mouse IgG were considered as untreated controls. CXCR4 antibody treatment inhibited 143B-lacZ cell homing to the lung and had a mild inhibitory effect on primary tumor osteolysis and growth $[31,32]$. Thus, the results of the present study demonstrate for the first time efficacy of the metastasis suppressive CXCR4 blocking principle in an orthotopic, spontaneously metastasizing OS model that mimics most aspects of the human disease.

\section{Materials and methods}

\section{Cell lines}

HOS cells were purchased from the American type culture collection (Rockville, MD) and 143B cells from the European collection of cell cultures (Salisbury, UK) [31]. Both cell lines were grown in Dulbecco's modified Eagle medium (DMEM) (4.5 g/L glucose) and Ham F12 (F12) medium (1:1) supplemented with $2 \mathrm{mM}$ L-glutamine and $10 \%$ fetal calf serum (FCS) (GIBCO, Basel, Switzerland) (cell culture medium) in a humidified atmosphere of $95 \%$ air and $5 \% \mathrm{CO}_{2}$ at $37{ }^{\circ} \mathrm{C}$.

RNA isolation, reverse transcription (RT), and polymerase chain reaction (PCR)

Total RNA was isolated from individual cell lines with TriReagent (Sigma-Aldrich, St Louis, MO) according to the manufacturer's protocol. The RNA was quantified by measuring the absorption of extracts at $260 \mathrm{~nm}$. The integrity of the RNA was assessed by agarose gel-electrophoresis. The expression levels of mRNA encoding CXCR4 were determined by semi-quantitative RT/PCR with Gapdh transcripts as a reference. cDNA was synthesized from $1 \mu \mathrm{g}$ of total RNA with the High Capacity cDNA reverse transcription kit (Applied Biosystems Inc., Foster City, CA) and the protocol recommended by the supplier. PCR reactions of $50 \mu \mathrm{l}$ final volume contained $1 \mathrm{X}$ PCR buffer, $0.4 \mu \mathrm{l}$ of the RT reaction, $1.25 \mathrm{U}$ Taq polymerase (5Prime), each dNTP at $200 \mu \mathrm{M}$ concentration, and 
forward and reverse primers specific for GAPDH (Forward: 5'-TGA ACG GGA AGC TCA CTG GCA TGG -3'; Reverse: $5^{\prime}$-TGG GTG TCG CTG TTG AAG TCA GAG GA GA-3') and for CXCR4 (Forward: 5'- GAG TGC TCC AGT AGC CAC CGC ATC-3'; Reverse: $5^{\prime}$-TCC GTC ATG CTT CTC AGT TTC TTC TGG- $3^{\prime}$ ) encoding cDNA at $0.2 \mu \mathrm{M}$ concentration. After initial denaturation at $94{ }^{\circ} \mathrm{C}$ for $3 \mathrm{~min}$, cDNA was amplified by 27 (GAPDH) or 40 (CXCR4) PCR-cycles (denaturation at $94{ }^{\circ} \mathrm{C}$ for $40 \mathrm{~s}$, primer pair-dependent annealing at $67{ }^{\circ} \mathrm{C}(\mathrm{GAPDH})$ or $69{ }^{\circ} \mathrm{C}$ (CXCR4) for $40 \mathrm{~s}$, and elongation at $72{ }^{\circ} \mathrm{C}$ for $20 \mathrm{~s}$ ) followed by final elongation at $72{ }^{\circ} \mathrm{C}$ for $7 \mathrm{~min}$. PCR products were analyzed by agarose gel electrophoresis.

\section{FACS analysis of CXCR4 expression}

HOS and 143B cells grown to $50 \%$ confluence were detached with MACS buffer (PBS, $0.05 \%$ ethylenediaminetetraacetic acid (EDTA) and $2 \%$ FCS). They were then transferred to $5 \mathrm{ml}$ Polystyrene FACS tubes (BD FALCON $^{\mathrm{TM}}$, Franklin Lakes, NJ, USA) collected by centrifugation at $1,600 \mathrm{rpm}$ and $4{ }^{\circ} \mathrm{C}$ for $5 \mathrm{~min}$ and resuspended. Subsequently, the cells were incubated with $5 \mu \mathrm{g} / \mathrm{ml}$ of CXCR4 antibody, clone 12G5 (R\&D System, Abingdon, UK), at $4{ }^{\circ} \mathrm{C}$ for $30 \mathrm{~min}$. The cells were then washed twice with PBS and incubated at $4{ }^{\circ} \mathrm{C}$ for $20 \mathrm{~min}$ with $5 \mu \mathrm{g} / \mathrm{ml}$ of Alexa-conjugated goat anti-mouse $\mathrm{IgG}$ (Invitrogen, Carlsbad, CA). The cells were again washed twice with PBS and filtered through PARTEC CELL TRICS filters ( $50 \mu \mathrm{m}$ pore size, Görlitz, Germany). The percentage of cells expressing CXCR4 at the cell surface was determined with a FACS Aria/Calibur device (Beckton Dickinson, Allschwil, Switzeland).

\section{Analysis of CXCR4 signaling on Western Blots}

Cells were grown to $80 \%$ confluence and starved overnight in serum-free RPMI 1640 medium supplemented with $0.1 \%$ BSA (Sigma-Aldrich, St Louis, MO). The next day, the cells were detached (PBS with $0.05 \%$ EDTA), washed with PBS and stimulated in suspension with $100 \mathrm{ng} / \mathrm{ml}(12.5 \mathrm{nM})$ human recombinant CXCL12 (R\&D System, Abingdon, UK) at $37{ }^{\circ} \mathrm{C}$ for indicated time periods. Incubations were stopped by the addition of ice-cold PBS. Cells were then collected by centrifugation and lysed on ice for $45 \mathrm{~min}$ in buffer containing $\mathrm{NaF}$, orthovanadate and protease inhibitors (Roche, Basel, Switzerland). Cell lysates were cleared by centrifugation and mixed with an equal volume of $2 \times$ Laemmli sample buffer and incubated at $95{ }^{\circ} \mathrm{C}$ for $5 \mathrm{~min}$. Proteins were separated by SDSPAGE and transferred to nitrocellulose membranes. Phospho(p)-AKT, total AKT, p-ERK and total ERK were detected by incubation at $4{ }^{\circ} \mathrm{C}$ overnight with respective primary antibodies (Cell Signalling Technology Inc., Denver, MA) followed by incubation at RT for $1 \mathrm{~h}$ with secondary horseradish peroxidase conjugated anti-rabbit IgG (Santa Cruz Biotechnology Inc., Heidelberg, Germany). The proteins were then visualized with Immobilon chemiluminescence substrate (Millipore, Billerica) and quantified with a VersaDoc ${ }^{\mathrm{TM}}$ Imaging System (Bio-Rad Laboratories, Munich, Germany). Antibody blocking experiments were essentially performed like the stimulation experiments described above, except that 143B and HOS cells were kept adherent and pre-incubated $30^{\prime}$ with either $20 \mu \mathrm{g}$ (ml non-specific IgG (Jackson Immuno Research Rheinfeld, Switzerland) or $20 \mu \mathrm{g} / \mathrm{ml}$ of the highly specific 12G5 (anti-CXCR4) (R\&D System, Abingdon, UK), before stimulating for $10^{\prime}$ with $100 \mathrm{ng} / \mathrm{ml}$ SDF-1.

\section{Chemotaxis assay}

Chemotaxis assays were performed in triplicates in 48-well Boyden chambers (NeuroProbe, Gaithersburg, MD) with polyvinylpyrrolidone-free polycarbonate membranes of $8 \mu \mathrm{m}$ pore size. Cells grown to $50 \%$ confluence were harvested and resuspended in chemotaxis medium composed of DMEM and F12 medium (1:1) supplemented with $2 \mathrm{mM}$ L-glutamine and $0.2 \%$ FCS. $2 \times 10^{4}$ cells in $50 \mu \mathrm{L}$ chemotaxis medium were then added to the upper chamber of each well. Chemotaxis medium containing indicated concentrations of CXCL12 was added to the bottom chamber and chemotaxis was allowed under cell culture conditions for $4 \mathrm{~h}$. Cells adhering to the upper surface of the membrane were removed with a rubber policeman. Cells that had migrated through the filter and adhered to the lower surface of the membrane were fixed and stained with Diff-Quik $^{\circledR}$ (Medion Diagnostics AG, Düdingen Switzerland). They were counted under the microscope in five randomly selected fields at 100 -fold magnification.

LacZ gene transduction of OS cell lines

Retroviral particles for stable lacZ gene transduction (lacZretrovirus) of OS cell lines were prepared as reported [28]. HOS and 143B cells were grown to subconfluence and infected with lacZ-retrovirus by incubation for $2 \mathrm{~h}$ with $1 \mathrm{ml}$ virus-containing medium supplemented with $8 \mu \mathrm{g} / \mathrm{ml}$ polybrene (Sigma-Aldrich, St Louis, MO). The cells were then cultured for 7 days in medium containing $1,200 \mu \mathrm{g} / \mathrm{ml}$ G-418 (Invitrogen, Carlsbad, CA). Selection of lacZ transduced HOS (HOS-lacZ) and 143B (143B-lacZ) cells was monitored over time in aliquots of cells fixed with $4 \%$ formaldehyde for $20 \mathrm{~min}$ and then stained with X-gal at $37^{\circ} \mathrm{C}$ overnight. 
CXCR4 antibody treatment of SCID mice with intratibial $143 \mathrm{~B} /$ lac Z cell-derived OS

Female 6-8 week old severe combined immunodeficient (SCID) were purchased from Charles River Laboratories (Sulzfeld, Germany) and maintained under OHB conditions. Animal care and experimental procedures were in accordance with institutional guidelines and approved by the Ethics Committee of the Veterinary Department, Canton of Zurich, Switzerland (License Number 169/2009). 143B-lacZ cells were grown to subconfluence, detached with Trypsin/PBS/0.05\% EDTA and resuspended in PBS/ $0.05 \%$ EDTA. The single cell suspension contained $5 \times 10^{7}$ cells $/ \mathrm{ml}$. Ten microliter aliquots of the cell suspension equivalent to $5 \times 10^{5}$ cells were orthotopically injected into the medullar cavity of the left tibia of individual mice. After tumor cell injection, the mice were randomly divided into two groups. Treatment was initiated on the day of tumor cell injection and continued in 4-day intervals by bolus tail-vein injections of $100 \mu \mathrm{l}$ PBS containing $200 \mu \mathrm{g}$ mouse IgG (Jackson Immuno Research Rheinfeld, Switzerland) (control group) or $200 \mu \mathrm{g}$ CXCR4 12G5- antibodies (treatment group). Tumor development and osteolysis were monitored by X-ray once a week. Tumor volume was calculated from caliper rule measurements of the width and the length of the tumor-bearing tibia using the following formulas: leg volume $=$ length $\mathrm{x}(\text { width })^{2} \mathrm{x}$ 0.5 ; tumor volume $=$ leg Volume on day $\mathrm{X}-$ leg Volume on day $0 ;(\mathrm{X}=0,4,12,16$ and 20 days after tumor cell injection). All mice were sacrificed on experimental day 20 and the organs were prepared as reported [30]. Lungs were further prepared as previously reported [28, 33]. lacZ gene expressing metastatic tumor cells were visualized by $\mathrm{X}$ Gal staining as described [34]. Briefly, lung tissue was refixed with $2 \%$ formaldehyde and $0.2 \%$ glutaraldehyde in PBS at room temperature for $1 \mathrm{~h}$, washed 3 times with PBS and then stained in X-Gal solution at $37{ }^{\circ} \mathrm{C}$ for at least $3 \mathrm{~h}$.

Micrometastases, defined as indigo-blue stained foci smaller than $0.1 \mathrm{~mm}$ in diameter and macrometastases, defined as indigo-blue stained foci larger than $0.1 \mathrm{~mm}$ in diameter, on the surface of whole-mounts of lungs, were counted. Indigo-blue stained foci were counted on the surface of whole-mounts of lungs.
Fig. 1 Expression of CXCR4 in the parental low metastatic human osteosarcoma HOS cell line and the highly metastatic 143B subline. a semiquantitative RT/PCR analysis of Cxcr4 and Gapdh (reference) transcript levels in total RNA isolated from $50 \%(a)$ and $100 \%(b)$ confluent cells, $M$ marker lanes. b FACS analysis of indicated cell lines processed for cell surface immunostaining of CXCR4 in the absence (control) or presence (CXCR4+) of primary 12G5 CXCR4 antibodies a

HOS

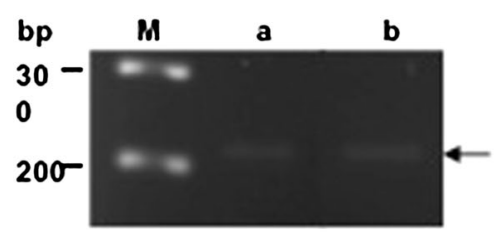

CXCR4
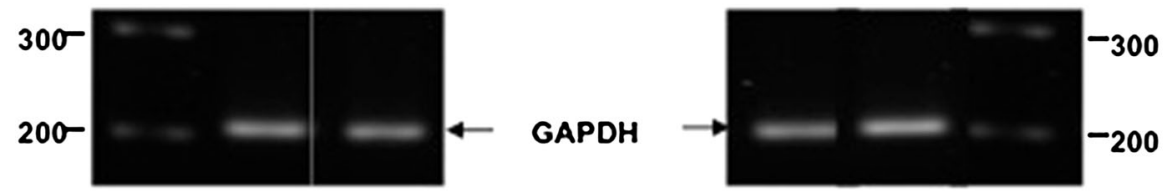

b

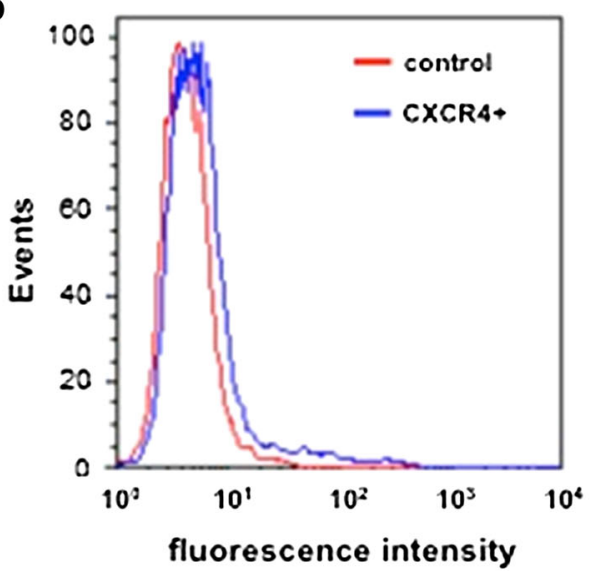

143B
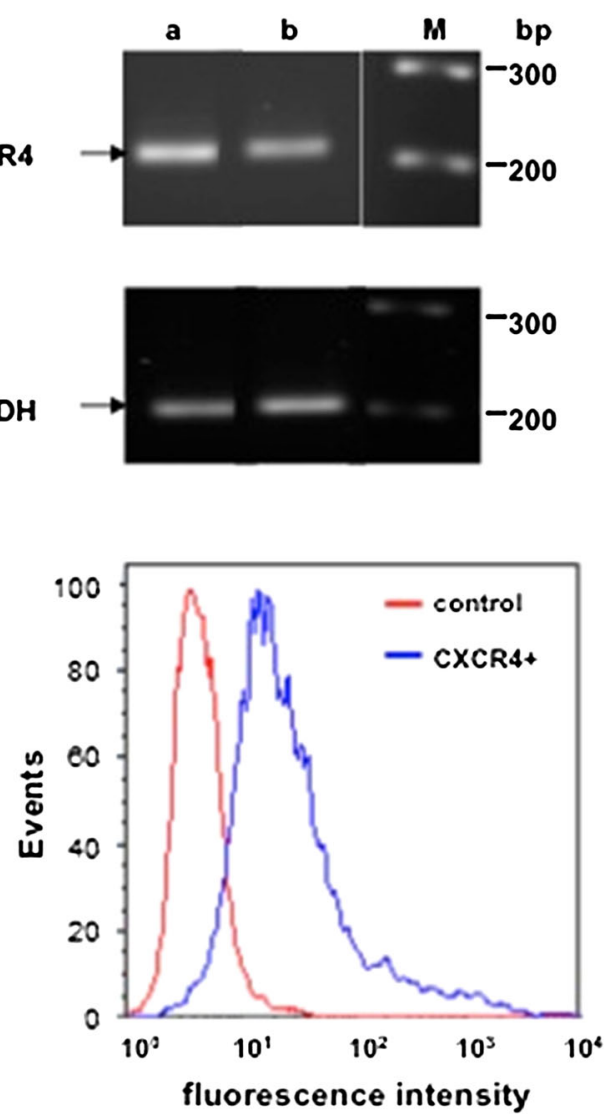
Fig. 2 Time-dependent stimulation of AKT and ERK phosphorylation by CXCL12 in HOS and 143B cells. a, b western blot analysis of extracts of HOS (a) and of 143B (c) cells incubated with $12.5 \mathrm{nM}$

CXCL12 for indicated time periods. The levels of $\mathrm{p}$-AKT and of total AKT (left panels) and of p-ERK and of total ERK (right panels) are shown. Data shown in $\mathbf{a}$ and $\mathbf{c}$ are representative for at least 3 independent experiments. b, d Quantitative analysis of the time-dependent stimulation of AKT (left) and ERK (right) phosphorylation in HOS (b) and143B (d) cells; Data indicate mean $\pm \operatorname{SEM}(n=3)$ levels of p-AKT and p-ERK normalized to total AKT and total ERK, respectively, at indicated time points; ${ }^{*} p \leq 0.05$ compared to control (C)

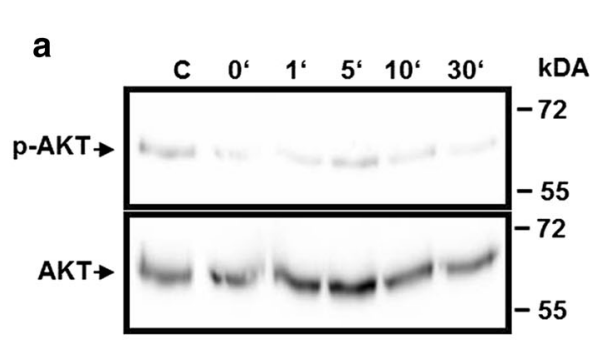

HOS
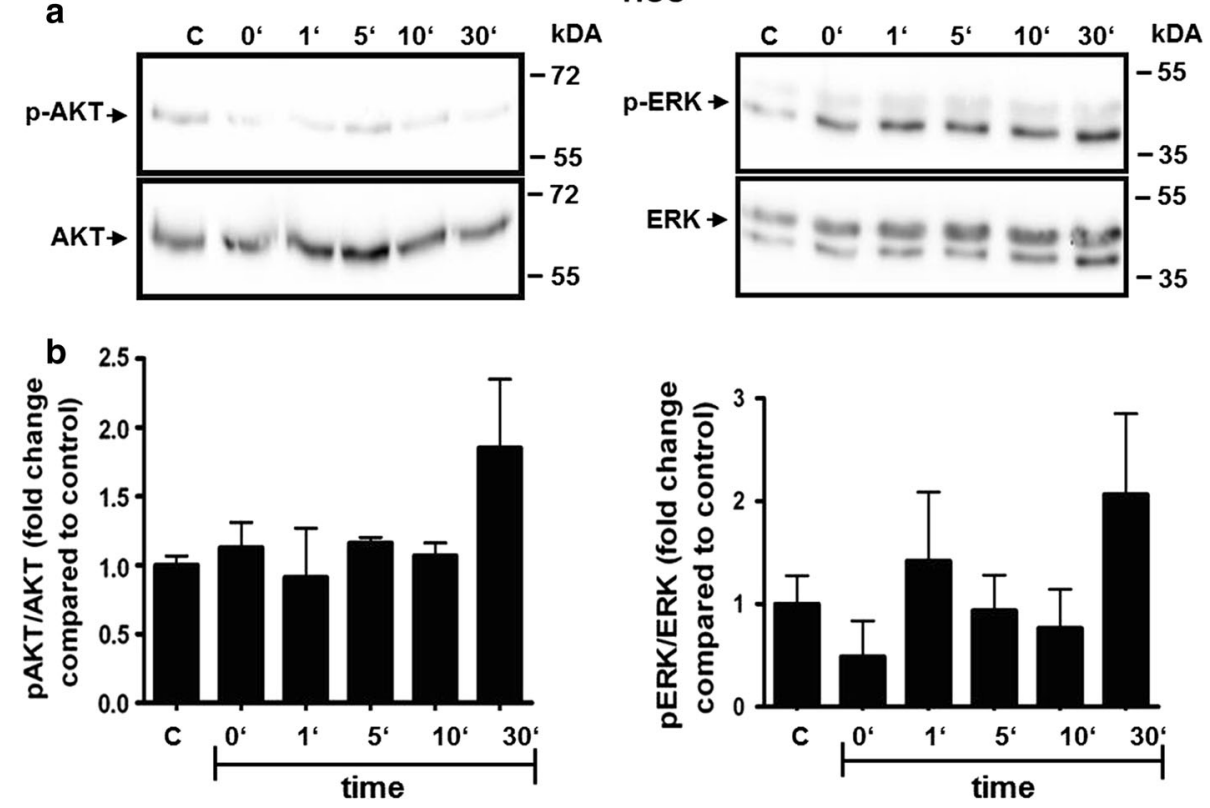

143B
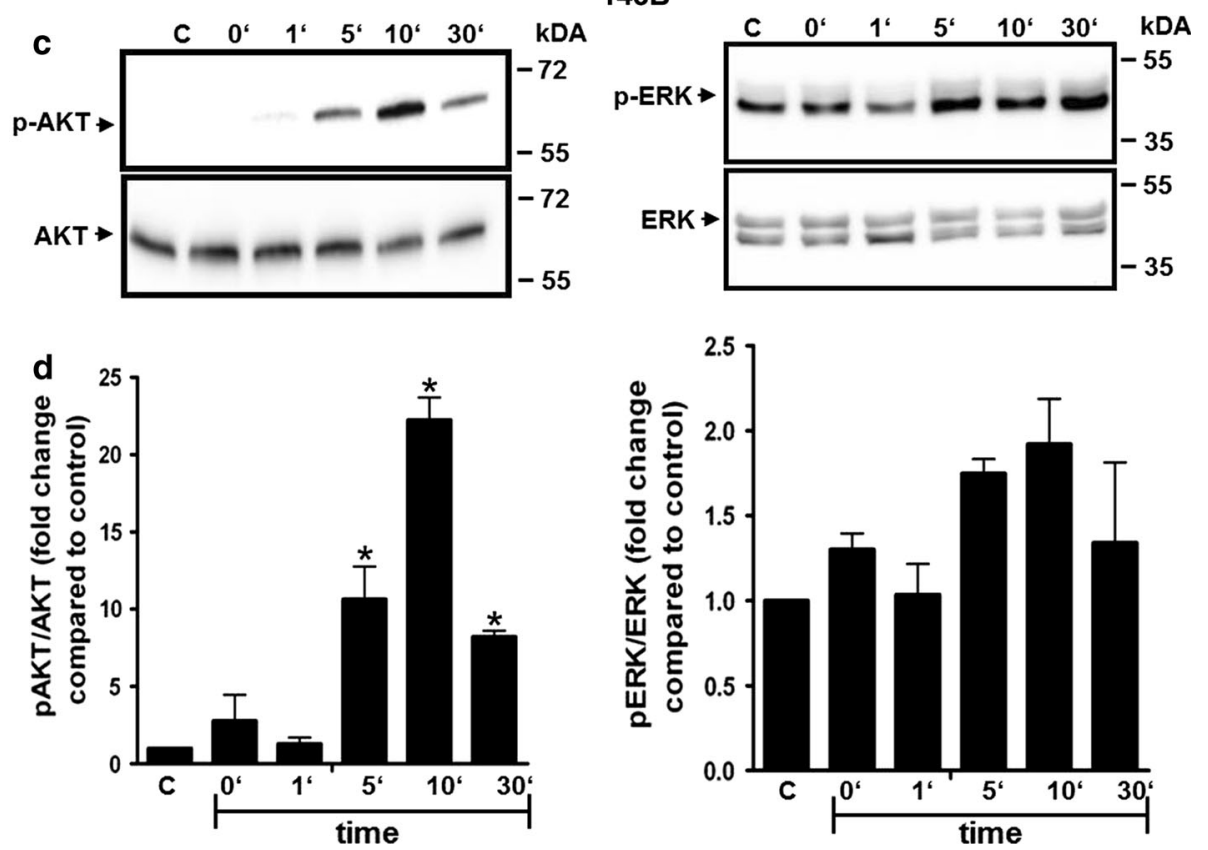

Statistical analysis

Results are presented as mean \pm standard error of the mean (SEM). The values of the primary tumor volume and the numbers of metastases were transformed to a logarithmic scale before they were analyzed for significance by 2-way ANOVA test with GraphPad Prism ${ }^{\circledR} 5.01$ software.

\section{Results}

Expression and signaling of CXCR4 in HOS and 143B cells

Semi-quantitative RT/PCR analysis of total RNA extracted from $50 \%$ to $100 \%$ confluent HOS and 143B cells 
Fig. 3 AKT signaling inhibition by the blocking antiCXCR4 antibody 12G5 in 143B and HOS cells. Shown are p-AKT and total AKT levels in HOS (a) and 143B (b) cells that were left untreated (ctr) or stimulated 10 min with SDF-1 $\left(10^{\prime} \mathrm{SDF}-1\right)$ and were preincubated with $\mathrm{IgG}$ (ctr $+\mathrm{IgG}$ and $10^{\prime}$ SDF-1 + IgG) or $12 \mathrm{G} 5$ $\left(\mathrm{ctr}+12 \mathrm{G} 5\right.$ and $10^{\prime}$ SDF$1+12 \mathrm{G} 5)$ antibodies. Data indicate mean \pm SEM $(n=3)$ levels of p-AKT normalized to total AKT $(* p \leq 0.05$ compared to control $10^{\prime} \mathrm{SDF}-1$ stimulation)

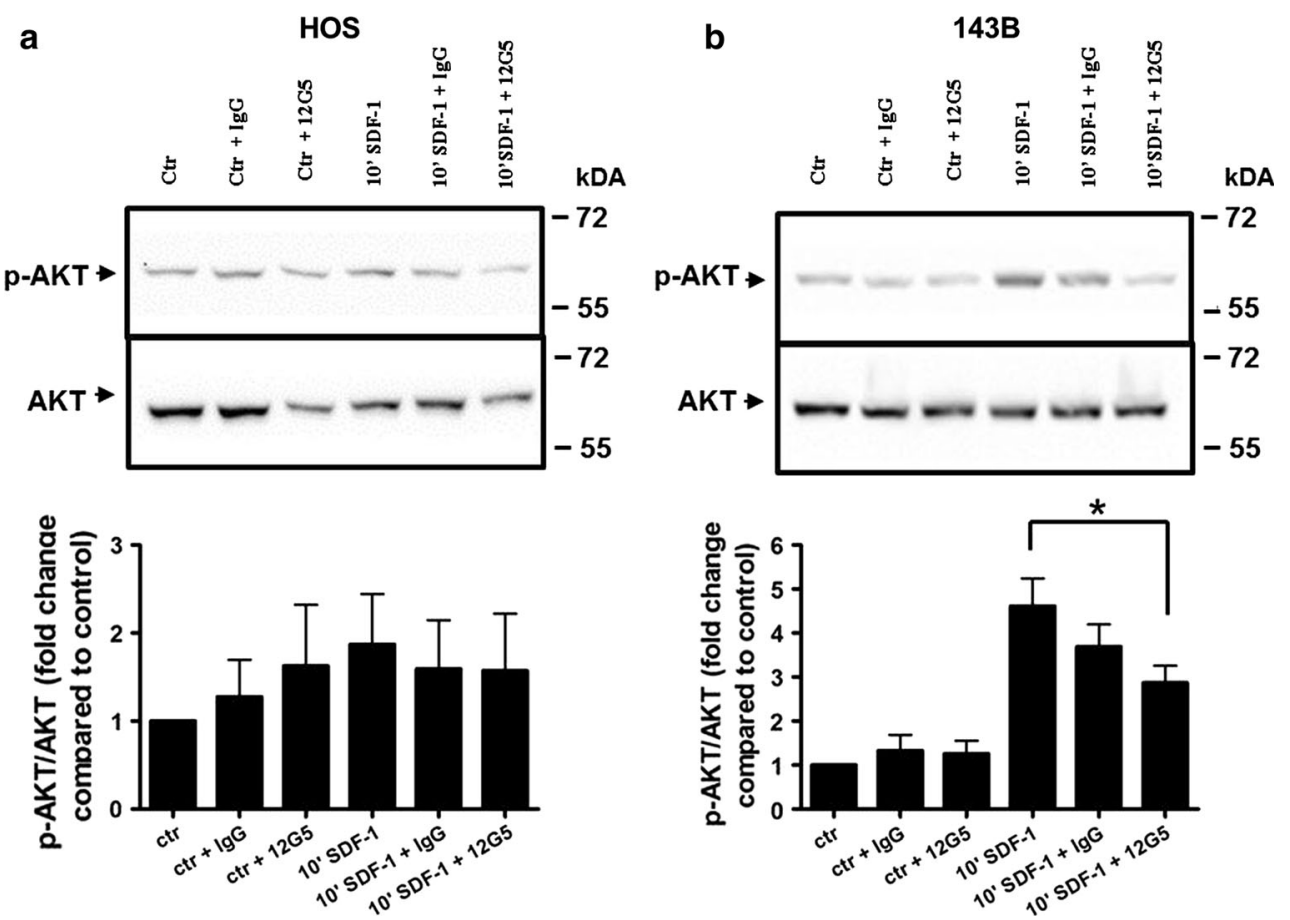

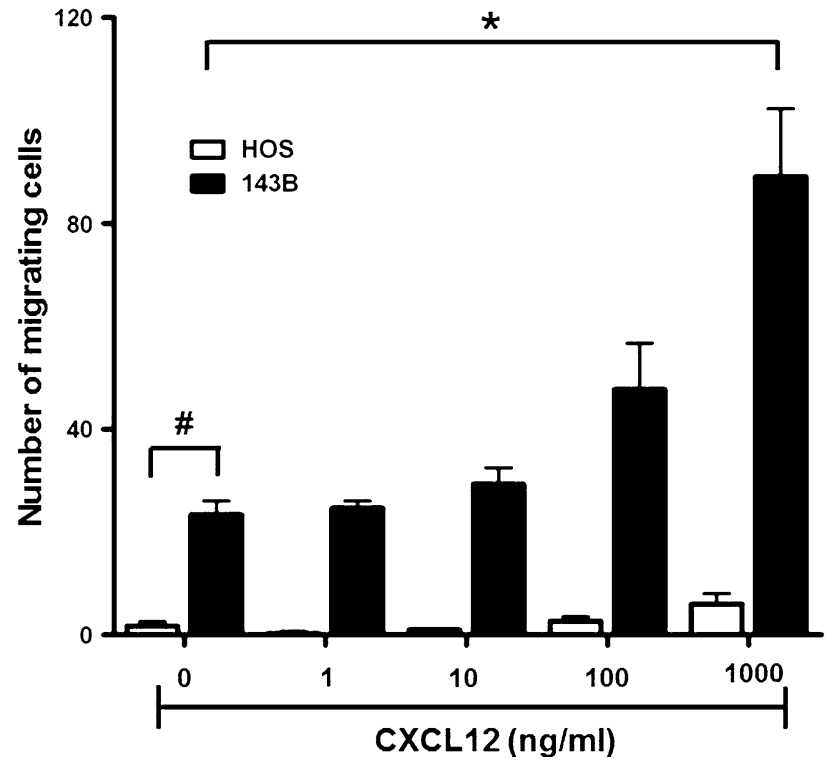

Fig. 4 CXCL12 dose-dependent CXCR4-mediated chemotaxis of HOS and 143B cells. Cells were seeded in 48-well Boyden chambers on membranes of $8 \mu \mathrm{m}$ pore size and chemotaxis to indicated concentrations of CXCL12 added to the medium in the bottom chamber was allowed for $4 \mathrm{~h}$. Non-migrating cells adhering to the upper surface of the membrane were removed and cells that had migrated across the membrane and adhered to the bottom surface were fixed, stained with Diff Quick ${ }^{\circledR}$ and counted under the microscope. $* p \leq 0.05$ compared to $143 \mathrm{~B}$ cells incubated in the absence of CXCL12; ${ }^{\#} p \leq 0.05$ compared to HOS cells in the absence of CXCL12 detected only trace amounts of CXCR4-encoding transcripts in HOS cells compared to those observed in 143B cells (Fig. 1a). These results were in good agreement with the expression of CXCR4 on the surface of HOS and 143B cells analyzed by FACS (Fig. 1b). CXCR4 cell surface immunostaining was only recognized in $3 \pm 1 \%$ of the HOS cells analyzed, whereas $75 \pm 5 \%$ of the $143 \mathrm{~B}$ cells expressed immune-detectable CXCR4 at the cell surface.

This pattern of CXCR4 expression in HOS and 143B cells was confirmed by the signaling response of the cells to CXCL12. Time-dependent transient phosphorylation of AKT and ERK upon stimulation with $100 \mathrm{ng} / \mathrm{ml} \mathrm{CXCL12}$ was only observed in 143B cells (Fig. 2c). Maximal stimulation was observed after 10 min of incubation with CXCL12 and amounted to a 22- and 2-fold increase of phospho-AKT and phospho-ERK, respectively, over basal levels when normalized to total AKT and ERK (Fig. 2d). HOS cells did not show any significant increase in phosphorylation of AKT and ERK when compared to the control cells after normalization to total AKT and ERK(Fig. 2a, b). CXCR4 dependent AKT signaling could by efficiently blocked in 143B cells by 12 G5 while HOS did not show any stimulation and consequently any inhibition upon pre-incubation with 12G5 (Fig. 3a, b).

\section{CXCL12-provoked chemotaxis of HOS and 143B cells}

Migratory activity of the cell lines, considered as an in vitro indicator of in vivo metastatic activity, was 


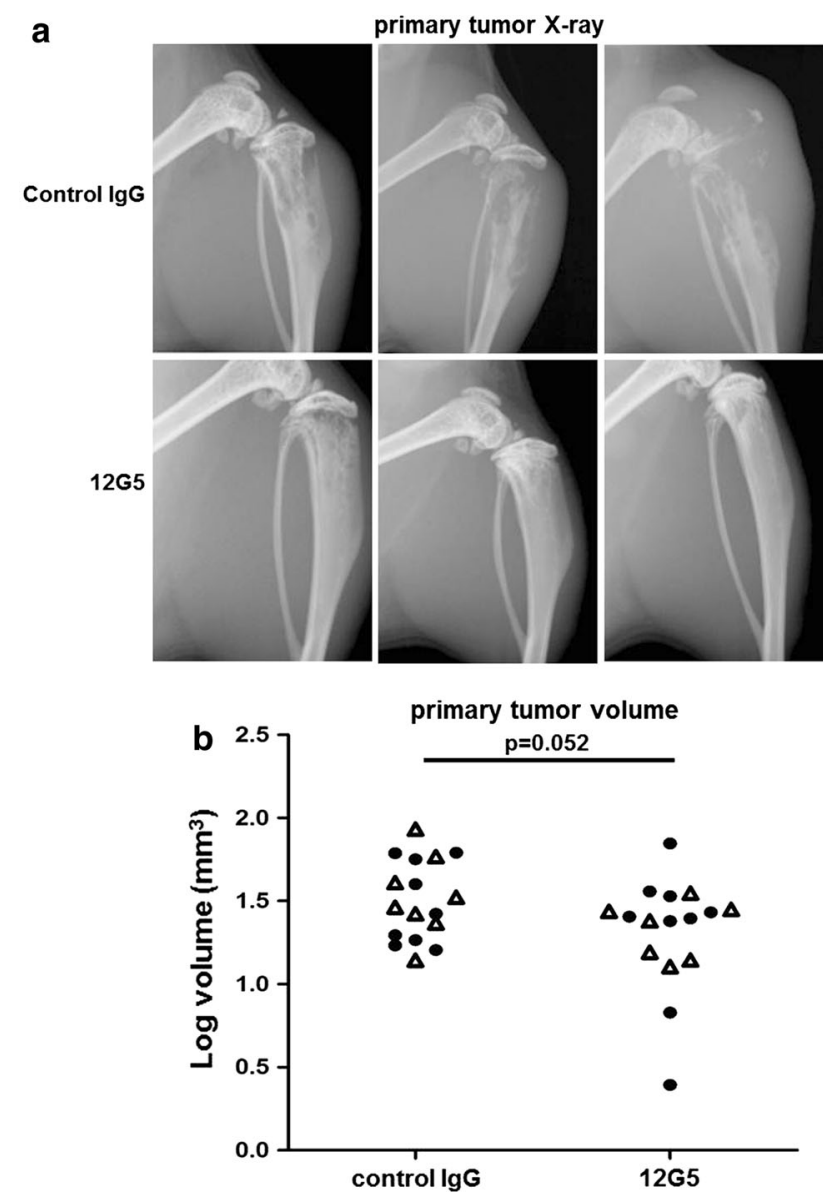

Fig. 5 Effects of repetitive systemic administration of 12G5 CXCR4blocking antibodies on intratibial primary tumor development of 143B-lacZ osteosarcoma cell xenografts. a Representative X-ray images of 143B-lac $Z$ cell-derived tumors in severe combined immunodeficient mice treated with control mouse IgG (top panels) or with 12G5 CXCR4 antibodies (bottom panels). b Primary tumor volumes calculated from caliper measurements of tumor bearing tibiae in control mouse IgG- or 12G5 antibody-treated mice. The results are from two independent experiments with 7 (first experiment) and 6 (second treatment) (open triangle) and 9 (filled circle) mice per indicated group

assessed in a Boyden chamber migration assay in the absence and presence of CXCL12 in the lower chamber. The basal motility, indicated by the number of cells migrating across the filter in the absence of CXCL12, was 15-times higher in 143B than in HOS cells (Fig. 4). A maximal 3.7-fold increase in the number of migrating 143B cells in response to $1 \mu \mathrm{g} / \mathrm{mL}$ CXCL12 in the lower compartment of the Boyden chamber reflected the expected chemotactic response. HOS cells with only hardly detectable CXCR4 expression, on the other hand, showed only a minimal chemotactic response to CXCL12.

Altogether, the findings were consistent with the reported high metastatic activity of 143B compared to HOS cells and suggested that the CXCL12-stimulated CXCR4 signaling and migration activity of $143 \mathrm{~B}$ cells contributed to their in vivo metastatic potential. Thus, the mAb $12 \mathrm{G} 5$ to human CXCR4, reported to inhibit the binding of human CXCL12 and downstream signaling of human CXCR4, was used to investigate the CXCR4 blocking principle in the 143B-lacZ cell-derived intratibial, spontaneously metastasizing OS mouse model, mimicking the human condition.

Repetitive systemic treatment of SCID mice suffering from intratibial 143B-lacZ OS xenografts with CXCR4blocking antibodies diminishes osteolysis and inhibits lung micro-metastasis

Osteolysis in the proximal tibia, visualized by $\mathrm{X}$-ray before sacrifice of the mice on day 20 after 143B-lacZ cell injection, was considerably less pronounced in animals treated in 4-day intervals by tail-vein injections of $200 \mu \mathrm{g}$ $\mathrm{mAb} 12 \mathrm{G} 5$ compared to mice receiving the same doses of control mouse IgG (Fig. 5a). Mice treated with mAb 12G5 showed also a tendency $(p=0.052)$ to tumors with a smaller volume than those of control mouse IgG-treated animals (Fig. 5b). Thus, repetitive tail-vein bolus injection of CXCR4 antibodies inhibited the development of OS in the tibia from 143B-lacZ xenografts during the experimental period of 20 days. The ex vivo analysis of the X-gal stained metastatic lesions on lung surfaces showed that the repetitive treatment of the mice with mAb 12G5 compared to the treatment with control $\operatorname{IgG}$ had no effect on the number of outgrown lung macrometastases $(>0.1 \mathrm{~mm}$ in diameter) at sacrifice on day 20 after intratibial tumor cell injection (Fig. 6a). However, mice treated with mAb 12G5 had significantly $(p<0.01)$ lower numbers of apparently minimally growing micro-metastases $(<0.1 \mathrm{~mm}$ in diameter) than mice treated with mouse IgG (Fig. 6b), indicating that circulating CXCR4-blocking antibodies effectively inhibited the homing to the lung of 143B-lacZ cells disseminating from primary intratibial tumors.

\section{Discussion}

Metastasis predominantly to the lung remains the leading cause of death in OS patients despite the implementation of neoadjuvant/adjuvant chemotherapy in the late 1970s [7]. Consequently, new treatment modalities targeting the complex metastatic process are needed. The chemokine CXCL12 has been recognized as an important chemoattractant of CXCR4 expressing metastasizing cells of numerous tumor types. CXCL12 has also been proposed as molecular cue guiding metastasizing OS cells to the lung where CXCL12 is expressed [12, 21, 35, 36]. Studies in OS mouse models of experimental metastasis, revealed by intravenous injections of tumor cells, indeed demonstrated 
Fig. 6 Micrometastasisinhibiting effects of repetitive administration of CXCR4blocking 12G5 antibodies in mice with intratibial 143B-lacZ cell-derived tumors.

a Representative images of whole mounts of lungs of mice treated with mouse IgG (left) or with 12G5 CXCR4 antibodies (right). X-gal stained metastases appear in blue. b Microscopic images of representative areas of lung whole mounts (4-fold magnification, size

bar $=10 \mu \mathrm{m}$ ) of 143B-lacZ cell tumor-bearing mice treated with mouse IgG (left) or with 12G5 CXCR4 antibodies (right). Arrows point to X-gal-stained micrometastases in blue. The total numbers of micrometastases per lung of indicated mice treated with mouse $\mathrm{IgG}$ or with $12 \mathrm{G} 5$ antibodies are shown in the bottom panel. The results were obtained in two independent experiments with 7 (open triangle) and 9 (filled circle) mice per indicated group. $p<0.01$ was considered as statistically significant

\section{a \\ Macrometastases}
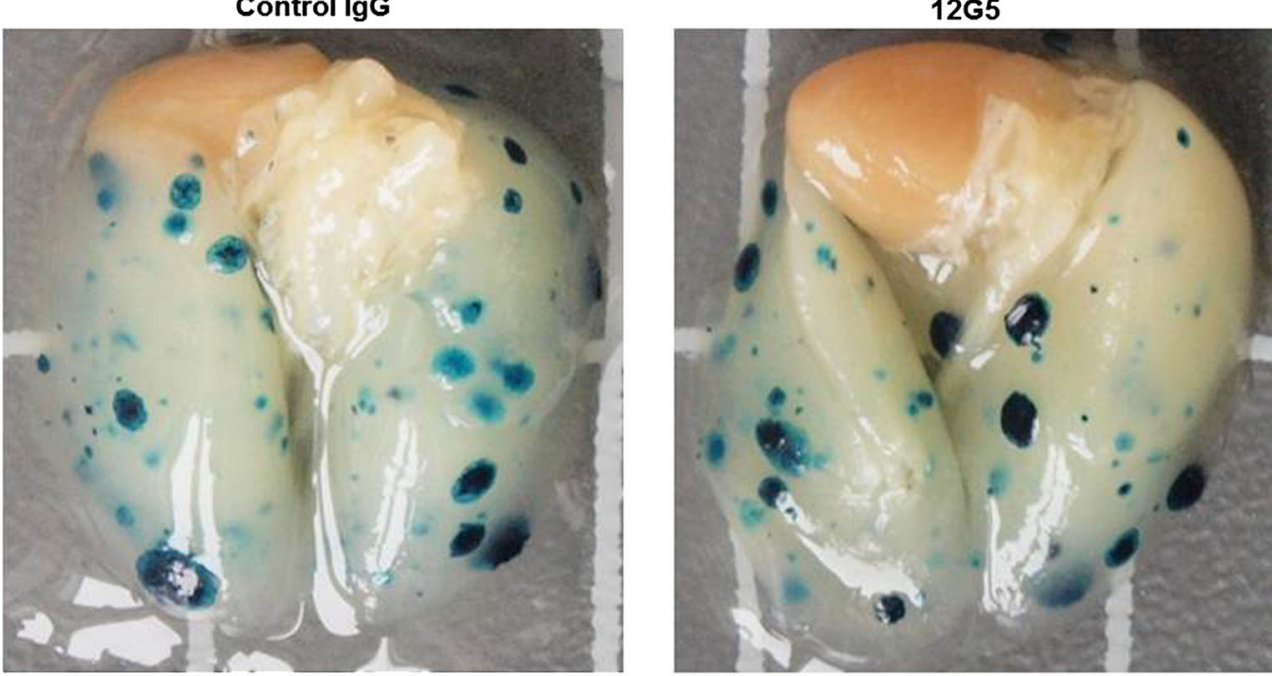

b

Micrometastases
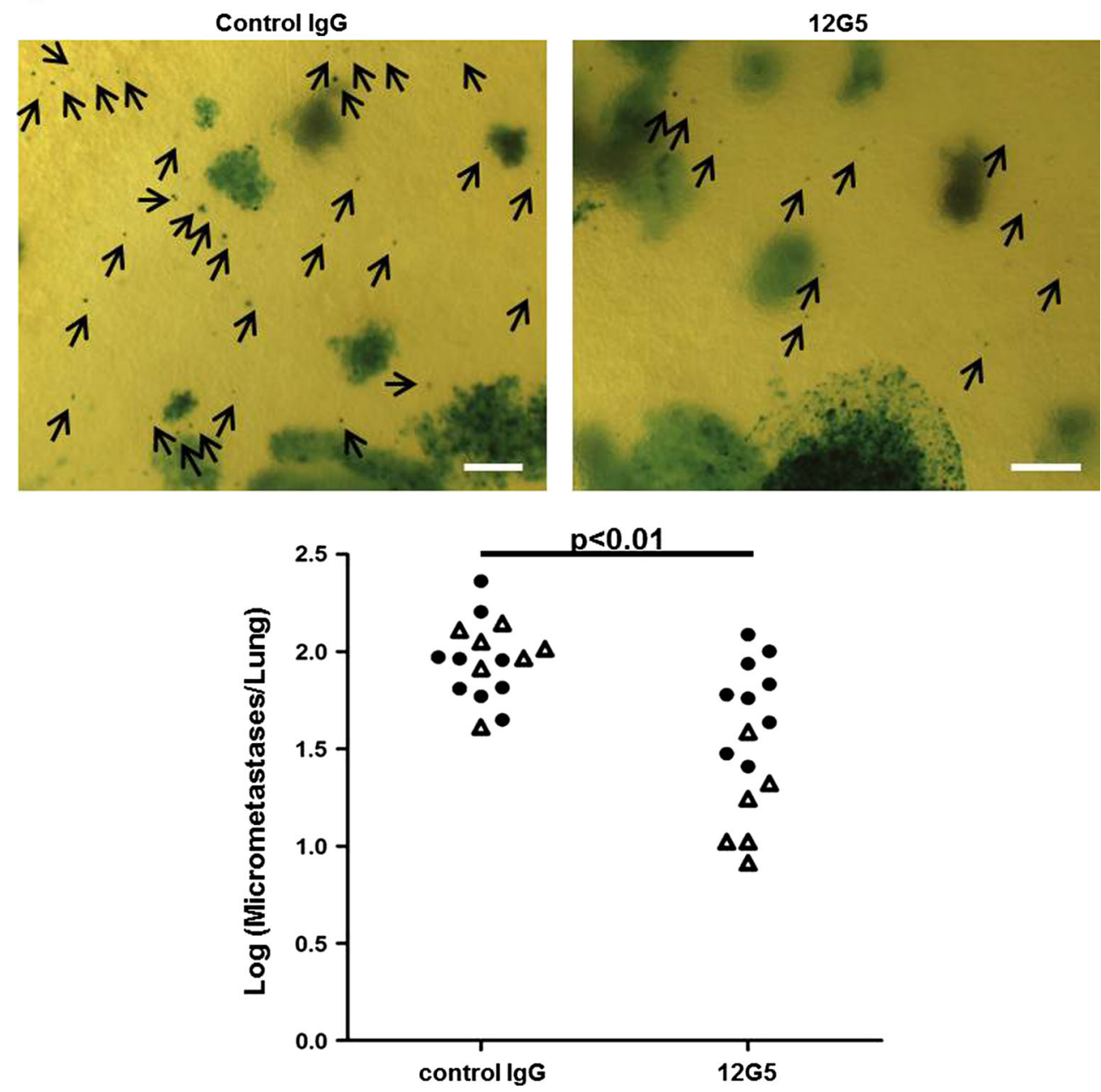

the relevance of the CXCL12/CXCR4 axis in OS metastasis [24-26]. These were seminal and valuable proof of principle studies despite the fact that they employed mouse models of experimental metastasis, which rather incompletely reproduce the complex cascade of biological processes that are crucial in OS metastasis. In the present 
study, we therefore reinvestigated the CXCR4-blocking principle for OS treatment in the human 143B OS cell linederived intratibial xenograft model in SCID mice that closely mimics the human disease with metastasis from the primary bone tumor to the lung.

The results presented here demonstrate that targeting the CXCL12/CXCR4 axis in the orthotopic mouse model of spontaneously metastasizing OS by repetitive tail-vein bolus injections of the anti-CXCR4 mAb 12G5 slowed down the osteolytic tumor development and, even more importantly in the context of OS, significantly reduced the number of primary tumor cells that disseminated to the lung where they were recognized as apparently nongrowing micrometastases. This is an important finding in view of urgently needed novel strategies for more effective treatment of OS patients with metastatic disease. Bruland and co-workers could further demonstrate that the number of circulating micro-metastasis positively correlated with OS patient outcome [37] underlining the importance of finding efficient treatment modalities against these circulating cells as shown in the present study. However, the applied antibody treatment did not significantly affect the number of outgrowing lung macro-metastases. These observations likely reflect some limitations of the here used experimental OS mouse model, which is dependent on intratibial injection of the highly aggressive metastatic 143B OS cells. Despite taking any possible measures to avoid the escape of tumor cells from the injection site, we believe that it is almost inevitable that a small number of injected cells end up in the circulation and finally grow as metastases in the lung before effective onset of the antibody therapy. In an attempt to minimize the consequences of the above mentioned cell leakage and to further estimate the full potential of the herein presented antibody therapy strategy an upfront study administrating antibody prior to it cell injection is foreseeable. The evident disadvantage of such a treatment modality would be its lack of reflection of the patient situation. Moreover, in interpreting the data, it also has to be considered that approximately $25 \%$ of $143 \mathrm{~B}$ cells analyzed by FACS before injection showed at least temporarily non-detectable CXCR4 expression at the cell surface, and it is conceivable that such cells were inefficiently targeted by CXCR4 antibodies. Nevertheless, the number of lung micro-metastases was significantly reduced by antibody treatment, indicating that the CXCR4-blocking antibody 12G5 effectively interfered with the homing of metastasizing 143B cells to the lung, most likely through binding to the cells in the circulation. In addition we could show that the anti-CXCR4 antibody 12G5 efficiently blocked CXCL12 dependent AKT signaling, involved in migration and cell survival, essential for metastatic spread, in the highly metastatic human OS cells 143B, but not in their parental non-metastatic HOS cells which lack CXCR4 and are therefore unresponsive towards CXCL12. Interestingly, the metastasis inhibiting potential of mAb12G5 treatment observed in the present study was comparable to that reported for a tumor challenging experiment performed by Bertolini and co-workers [38]. In this report human Non-Hodgkin's Lymphoma cells, pre-treated with $\mathrm{mAb} 12 \mathrm{G} 5$, were tail- vein injected into immunocompromised NOD/SCID mice and animals having received antibody-treated cells showed a significantly longer survival compared to control animals. In the same study diminished primary tumor development was observed at a moderate level, which is in agreement with the findings of the present study. Thus, all these observations taken together suggest, that, in the present study, tail-vein administered CXCR4 antibodies most effectively interfered with CXCL12-guided metastasizing, CXCR4 expressing 143B cells in the circulation. Furthermore we cannot exclude that also other mechanisms like 12G5 mediated ADCC (antibody dependent cellular cytotoxicity) via monocyte/macrophages or NK cells lead to cancer cell killing in the bloodstream. There the cells were likely exposed to the temporarily highest concentrations of the antibodies on their way to the lungs. In the developing primary bone tumor and in growing metastases in the lung, on the other hand, the antibodies likely had poor access to the tumor cells due to slow and inefficient delivery mechanisms in these tissues for proteins of that size. Consequently, the growth of tumor cells in the bone and in lung metastases was much less effectively inhibited by CXCR4 antibodies than CXCL12-guided and CXCR4-mediated chemotaxis of metastasizing tumor cells in the circulation.

In conclusion, the results of the present study demonstrate that a metastasis-suppressive CXCR4-blocking strategy is effective in an intratibial mouse model of spontaneously metastasizing, CXCR4-expressing OS. Consequently, the development of high affinity CXCR4blocking agents with a long half-life and in formulations suitable for selective targeting of metastasizing OS cells in the primary tumor, the circulation and secondary organs appears to be a worthwhile approach to increase the efficacy of the treatment of metastasizing OS in combination with current treatment modalities or novel drugs.

Acknowledgments We thank Josefine Bertz and Christopher Buehler for their excellent technical support and their generous help. This study was supported by the Zurcher Krebsliga (Zurich, Switzerland), the High Specialized Medicine (HSM) program for the support of musculoskeletal Oncology research of the local government of Zurich, the University of Zurich, the Schweizerischer Verein Balgrist (Zurich, Switzerland), the Walter L. \& Johanna Wolf Foundation (Zurich, Switzerland) and the Lydia Hochstrasser Stiftung (Zurich, Switzerland).

Conflict of interest The authors declare that they have no conflict of interest. 
Open Access This article is distributed under the terms of the Creative Commons Attribution License which permits any use, distribution, and reproduction in any medium, provided the original author(s) and the source are credited.

\section{References}

1. Federman N, Bernthal N, Eilber FC, Tap WD (2009) The multidisciplinary management of osteosarcoma. Curr Treat Options Oncol 10(1-2):82-93. doi:10.1007/s11864-009-0087-3

2. Picci P (2007) Osteosarcoma (osteogenic sarcoma). Orphanet $\mathbf{J}$ Rare Dis 2:6

3. Carrle D, Bielack SS (2006) Current strategies of chemotherapy in osteosarcoma. Int Orthop 30(6):445-451. doi:10.1007/s00264006-0192-x

4. Mercuri M, Capanna R, Manfrini M, Bacci G, Picci P, Ruggieri P, Ferruzzi A, Ferraro A, Donati D, Biagini R et al (1991) The management of malignant bone tumors in children and adolescents. Clin Orthop Relat Res 264:156-168

5. Jaffe N, Carrasco H, Raymond K, Ayala A, Eftekhari F (2002) Can cure in patients with osteosarcoma be achieved exclusively with chemotherapy and abrogation of surgery? Cancer 95(10):2202-2210

6. Bacci G, Ferrari S, Longhi A, Perin S, Forni C, Fabbri N, Salduca N, Versari M, Smith KV (2001) Pattern of relapse in patients with osteosarcoma of the extremities treated with neoadjuvant chemotherapy. Eur J Cancer 37(1):32-38. doi:S0959-8049(00)00361-0

7. Yonemoto T, Tatezaki S, Ishii T, Satoh T, Kimura H, Iwai N (1998) Prognosis of osteosarcoma with pulmonary metastases at initial presentation is not dismal. Clin Orthop Relat Res 349:194-199

8. Gorlick R, Anderson P, Andrulis I, Arndt C, Beardsley GP, Bernstein M, Bridge J, Cheung NK, Dome JS, Ebb D, Gardner T, Gebhardt M, Grier H, Hansen M, Healey J, Helman L, Hock J, Houghton J, Houghton P, Huvos A, Khanna C, Kieran M, Kleinerman E, Ladanyi M, Lau C, Malkin D, Marina N, Meltzer P, Meyers P, Schofield D, Schwartz C, Smith MA, Toretsky J, Tsokos M, Wexler L, Wigginton J, Withrow S, Schoenfeldt M, Anderson B (2003) Biology of childhood osteogenic sarcoma and potential targets for therapeutic development: meeting summary. Clin Cancer Res 9(15):5442-5453

9. Gorlick R, Khanna C (2010) Osteosarcoma. J Bone Miner Res 25(4):683-691. doi:10.1002/jbmr.77

10. Balkwill F (2003) Chemokine biology in cancer. Semin Immunol 15(1):49-55. doi:S1044532302001276

11. Nguyen DX, Bos PD, Massague J (2009) Metastasis: from dissemination to organ-specific colonization. Nat Rev Cancer 9(4):274-284. doi:10.1038/nrc2622

12. Muller A, Homey B, Soto H, Ge N, Catron D, Buchanan ME, McClanahan T, Murphy E, Yuan W, Wagner SN, Barrera JL, Mohar A, Verastegui E, Zlotnik A (2001) Involvement of chemokine receptors in breast cancer metastasis. Nature 410(6824):50-56. doi:10.1038/35065016-35065016

13. Rueda P, Balabanian K, Lagane B, Staropoli I, Chow K, Levoye A, Laguri C, Sadir R, Delaunay T, Izquierdo E, Pablos JL, Lendinez E, Caruz A, Franco D, Baleux F, Lortat-Jacob H, Arenzana-Seisdedos F (2008) The CXCL12gamma chemokine displays unprecedented structural and functional properties that make it a paradigm of chemoattractant proteins. PLoS ONE 3(7):e2543. doi:10.1371/journal.pone.0002543

14. Balkwill F (2004) Cancer and the chemokine network. Nat Rev Cancer 4(7):540-550

15. Balkwill $\mathrm{F}$ (2004) The significance of cancer cell expression of the chemokine receptor CXCR4. Semin Cancer Biol 14(3):171-179

16. Nagasawa $T$, Hirota $S$, Tachibana $K$, Takakura N, Nishikawa $S$, Kitamura Y, Yoshida N, Kikutani H, Kishimoto T (1996) Defects of
B-cell lymphopoiesis and bone-marrow myelopoiesis in mice lacking the CXC chemokine PBSF/SDF-1. Nature 382(6592):635-638. doi: $10.1038 / 382635 \mathrm{a} 0$

17. Ma Q, Jones D, Borghesani PR, Segal RA, Nagasawa T, Kishimoto T, Bronson RT, Springer TA (1998) Impaired B-lymphopoiesis, myelopoiesis, and derailed cerebellar neuron migration in CXCR4- and SDF-1-deficient mice. Proc Natl Acad Sci USA 95(16):9448-9453

18. Kucia M, Jankowski K, Reca R, Wysoczynski M, Bandura L, Allendorf DJ, Zhang J, Ratajczak J, Ratajczak MZ (2004) CXCR4-SDF-1 signalling, locomotion, chemotaxis and adhesion. J Mol Histol 35(3):233-245

19. Majka M, Ratajczak J, Kowalska MA, Ratajczak MZ (2000) Binding of stromal derived factor-1alpha (SDF-1alpha) to CXCR4 chemokine receptor in normal human megakaryoblasts but not in platelets induces phosphorylation of mitogen-activated protein kinase p42/44 (MAPK), ELK-1 transcription factor and serine/threonine kinase AKT. Eur J Haematol 64(3):164-172

20. Roland J, Murphy BJ, Ahr B, Robert-Hebmann V, Delauzun V, Nye KE, Devaux C (2002) Biard-Piechaczyk M (2003) Role of the intracellular domains of CXCR4 in SDF-1-mediated signaling. Blood 101(2):399-406. doi:10.1182/blood-2002-03-09782002-03-0978

21. Laverdiere C, Hoang BH, Yang R, Sowers R, Qin J, Meyers PA, Huvos AG, Healey JH, Gorlick R (2005) Messenger RNA expression levels of CXCR4 correlate with metastatic behavior and outcome in patients with osteosarcoma. Clin Cancer Res 11(7):2561-2567. doi:10.1158/1078-0432.CCR-04-1089

22. Lin F, Zheng SE, Shen Z, Tang LN, Chen P, Sun YJ, Zhao H, Yao Y (2011) Relationships between levels of CXCR4 and VEGF and blood-borne metastasis and survival in patients with osteosarcoma. Med Oncol 28(2):649-653. doi:10.1007/s12032010-9493-4

23. Oda Y, Yamamoto H, Tamiya S, Matsuda S, Tanaka K, Yokoyama R, Iwamoto Y, Tsuneyoshi M (2006) CXCR4 and VEGF expression in the primary site and the metastatic site of human osteosarcoma: analysis within a group of patients, all of whom developed lung metastasis. Mod Pathol 19(5):738-745. doi:10. 1038/modpathol.3800587

24. de Nigris F, Rossiello R, Schiano C, Arra C, Williams-Ignarro S, Barbieri A, Lanza A, Balestrieri A, Giuliano MT, Ignarro LJ, Napoli C (2008) Deletion of Yin Yang 1 protein in osteosarcoma cells on cell invasion and CXCR4/angiogenesis and metastasis. Cancer Res 68(6):1797-1808. doi:10.1158/0008-5472.CAN-075582

25. Kim SY, Lee CH, Midura BV, Yeung C, Mendoza A, Hong SH, Ren L, Wong D, Korz W, Merzouk A, Salari H, Zhang H, Hwang ST, Khanna C, Helman LJ (2008) Inhibition of the CXCR4/ CXCL12 chemokine pathway reduces the development of murine pulmonary metastases. Clin Exp Metastasis 25(3):201-211. doi:10.1007/s10585-007-9133-3

26. Perissinotto E, Cavalloni G, Leone F, Fonsato V, Mitola S, Grignani G, Surrenti N, Sangiolo D, Bussolino F, Piacibello W, Aglietta M (2005) Involvement of chemokine receptor 4/stromal cell-derived factor 1 system during osteosarcoma tumor progression. Clin Cancer Res 11(2 Pt 1):490-497

27. Rhim JS, Kim CM, Arnstein P, Huebner RJ, Weisburger EK, Nelson Ress WA (1975) Transformation of human osteosarcoma cells by a chemical carcinogen. J Natl Cancer Inst 55(6):1291-1294

28. Arlt MJ, Banke IJ, Walters DK, Puskas GJ, Steinmann P, Muff R, Born W, Fuchs B (2011) LacZ transgene expression in the subcutaneous Dunn/LM8 osteosarcoma mouse model allows for the identification of micrometastasis. J Orthop Res 29(6):938-946. doi:10.1002/jor.21304

29. Endres MJ, Clapham PR, Marsh M, Ahuja M, Turner JD, McKnight A, Thomas JF, Stoebenau-Haggarty B, Choe S, Vance 
PJ, Wells TN, Power CA, Sutterwala SS, Doms RW, Landau NR, Hoxie JA (1996) CD4-independent infection by HIV-2 is mediated by fusin/CXCR4. Cell 87(4):745-756. doi:S00928674(00)81393-8

30. Yang H, Lan C, Xiao Y, Chen YH (2003) Antibody to CD14 like CXCR4-specific antibody 12G5 could inhibit CXCR4-dependent chemotaxis and HIV Env-mediated cell fusion. Immunol Lett 88(1):27-30. doi:S0165247803000488

31. Rhim JS, Cho HY, Huebner RJ (1975) Non-producer human cells induced by murine sarcoma virus. Int J Cancer 15(1):23-29

32. Berlin O, Samid D, Donthineni-Rao R, Akeson W, Amiel D, Woods VL Jr (1993) Development of a novel spontaneous metastasis model of human osteosarcoma transplanted orthotopically into bone of athymic mice. Cancer Res 53(20):4890-4895

33. Lietman SA, Joyce MJ (2010) Bone sarcomas: overview of management, with a focus on surgical treatment considerations. Cleve Clin J Med 77(Suppl 1):S8-S12. doi:10.3949/ccjm.77.s1. 02

34. Kruger A, Schirrmacher V, von Hoegen P (1994) Scattered micrometastases visualized at the single-cell level: detection and re- isolation of lacZ-labeled metastasized lymphoma cells. Int $\mathbf{J}$ Cancer 58(2):275-284

35. Taichman RS, Cooper C, Keller ET, Pienta KJ, Taichman NS, McCauley LK (2002) Use of the stromal cell-derived factor-1/ CXCR4 pathway in prostate cancer metastasis to bone. Cancer Res 62(6): 1832-1837

36. Burger M, Glodek A, Hartmann T, Schmitt-Graff A, Silberstein LE, Fujii N, Kipps TJ, Burger JA (2003) Functional expression of CXCR4 (CD184) on small-cell lung cancer cells mediates migration, integrin activation, and adhesion to stromal cells. Oncogene 22(50):8093-8101. doi:10.1038/sj.onc.12070971207097

37. Bruland OS, Hoifodt H, Saeter G, Smeland S, Fodstad O (2005) Hematogenous micrometastases in osteosarcoma patients. Clin Cancer Res 11(13):4666-4673. doi:10.1158/1078-0432.CCR-050165

38. Bertolini F, Dell'Agnola C, Mancuso P, Rabascio C, Burlini A, Monestiroli S, Gobbi A, Pruneri G, Martinelli G (2002) CXCR4 neutralization, a novel therapeutic approach for non-Hodgkin's lymphoma. Cancer Res 62(11):3106-3112 